\title{
Ciudades traducidas: Nueva York en Victoria Ocampo
}

\author{
Translated cities: New York in Victoria Ocampo
}

Cidades traduzidas: Nova lorque em Victoria Ocampo

\section{Sylvia Molloy}

NEW YORK UNIVERSITY, ESTADOS UNIDOS

Crítica y escritora. Hasta 2010, fue profesora en el Department of Spanish and Protuguese Languages and Literatures en New York University. Como crítica, es autora de La Diffusion de la littérature hispanoaméricaine en France au XXe siècle (PUF, 1972), Las letras de Borges (Sudamericana, 1979), At face value: Autobiographical writing in Spanish America (Cambridge UP, 1991) y Poses de fin de siglo: desbordes del género en la modernidad (Eterna Cadencia, 2013), y coeditora de los volúmenes Hispanisms and Homosexualities (con Robert McKee Irwin, Duke UP, 1998), Poéticas de la distancia. Adentro y afuera de la literatura argentina (con Mariano Siskind, Norma, 2006), y Women Writing in Latin America (con Sara Castro y Beatriz Sarlo, Westview, 1992). Dentro de su trabajo de ficción, destacan En breve cárcel (Seix Barral, 1981), El común olvido (Norma, 2002), Varia imaginación (Beatriz Viterbo, 2003), Desarticulaciones (Eterna Cadencia, 2010), y Vivir entre lenguas (Eterna Cadencia, 2015). Correo electrónico: sm3@nyu.edu 


\section{Resumen}

Ensayo inscrito en una pesquisa más amplia sobre cómo se construye la ciudad de Nueva York en el imaginario latinoamericano. De manera particular, se reflexiona sobre la manera en que Victoria Ocampo traduce - en el sentido más amplio del término - Nueva York para sí y para sus lectores cómplices, en sus autobiografías, cartas y testimonios. Así, se consignan intercambios notables con intelectuales contemporáneos: Waldo Frank y Roger Caillois, entre los considerados.

\author{
Palabras clave: Victoria \\ Ocampo; Nueva York- \\ imaginarios urbanos; traducción- \\ aspectos culturales; Waldo \\ Frank; Roger Caillois
}

\section{Abstract}

This essay is inscribed in a broader research on how New York city is built in the Latin American imaginary. Particularly, we reflect on the way in which Victoria Ocampo translates (in the broadest sense of the term) New York for herself and her complicit readers, in her autobiographies, letters, and testimonies. Thus, remarkable exchanges with contemporary scholars such as Waldo Frank and Roger Caillois, among those considered, are recorded.

Keywords: Victoria Ocampo; New York-urban imaginaries; translation-cultural aspects; Waldo Frank; Roger Caillois

\section{Resumo}

Ensaio inscrito em uma pesquisa mais ampla sobre como se constrói a cidade de Nova Iorque no imaginário latino-americano. Em particular, reflete-se sobre o jeito em que Victoria Ocampo traduz - no sentido mais amplo do termo - Nova Iorque para si e para os leitores cúmplices, nas suas autobiografias, cartas e depoimentos. Mesmo, consigam-se trocas notáveis com intelectuais contemporâneos: Waldo Frank e Roger Caillois, entre os considerados.

Palavras-chave: Victoria Ocampo; Nova Iorqueimaginários urbanos; traduçãoaspetos culturais; Waldo Frank; Roger Caillois

RECIBIDO: 15 DE JULIO DE 2016. ACEPTADO: 04 DE ENERO DE 2017. DISPONIBLE EN LÍNEA: 29 DE DICIEMBRE DE 2017

\section{Cómo citar este artículo:}

Molloy, Sylvia. "Ciudades traducidas: Nueva York en Victoria Ocampo". Cuadernos de

Literatura 21.42 (2017): 179-198. https://doi.org/10.11144/Javeriana.cl21-42.ctny 


\begin{abstract}
"No poder orientarse en una ciudad no significa gran cosa. Pero perderse en una ciudad, como quien se pierde en una selva, requiere toda una educación"
\end{abstract}

WALTER BENJAMIN, SENTIDO ÚNICO

Este trabajo es parte de una reflexión más amplia sobre cómo se construye la ciudad de Nueva York en el imaginario latinoamericano. Más específicamente: cómo transmite - es decir, cómo traduce - el viajero latinoamericano la ciudad extranjera para su consumo local y qué valor simbólico le da a ese trabajo de traducción, qué representatividad le adjudica al objeto traducido.

No pretendo postular un modelo de viaje latinoamericano porque tal cosa no existe. Elijo trabajar con Victoria Ocampo porque la composición de lugar que hace de Nueva York, entusiasta, pero sobre todo ansiosa, me parece particularmente rica en sentidos.

Una observación más: Ocampo viaja a Nueva York por primera vez en 1930, para continuar discusiones sobre la revista interamericana que habría de ser Sur y asentar un diálogo tanto entre culturas como entre ciudades. Pero cabe señalar además que este viaje ocurre justo después de algunas conversaciones de Ocampo con Le Corbusier — quien viajó a Buenos Aires en 1929-, sobre cómo "arreglar" la ciudad de Buenos Aires.

\title{
1930: An American Place
}

Victoria Ocampo viaja a Nueva York en 1930, a pedido de Waldo Frank. El viaje es resultado de una deliberada elección cultural, pero no por eso resulta menos difícil, ni menos perturbador. Al hablar de él en su autobiografía, Victoria Ocampo presenta este hecho más como desarraigo que como promesa de aventura: "[e]n la primavera de 1930 me arranqué de París para desembarcar, una mañana, de acuerdo con lo prometido, en Nueva York y hablar allí de la revista con Frank" (Testimonios $7^{a}$ serie 179). A pesar de esa promesa, el viaje se le hace cuesta arriba y es postergado varias veces: "[e]staba adherida a París sin decidirme a dar ese salto sobre el Atlántico en dirección opuesta a la de mi país. Me sentía condenada a ese salto, mucho más que deseosa de hacerlo" (Autobiografía VI 64). En su ensayo sobre Waldo Frank, Ocampo es aún más tajante, y presenta el viaje como sacrificio y ruptura desquiciadora. Recuerda cómo en París, luego de organizar una exposición de dibujos de Rabindranath Tagore, debe rechazar su invitación de viajar con él a la India para visitar Santiniketan: 
La idea de viajar con él me seducía no poco. Le expliqué los inconvenientes, mi viaje a Nueva York, Frank, la revista a que aspiraban los jóvenes argentinos. Él comprendió. [...] antes de decidirme a sacrificar una cosa o la otra, lo pasé muy mal. Hubiese deseado siempre lo imposible: no sacrificar nada de nada. Frank estaba lejos, Tagore cerca: lo veía diariamente. Él era incapaz de intentar convencerme de que la India podía interesarme más que los Estados Unidos y una hipotética revista. [...] Este fue mi primer gran sacrificio a la revista aún nonata. (Testimonios $10^{a}$ serie $93-94$ ).

"Me arranqué de París"; "adherida a París"; "condenada a ese salto"; "[l]o pasé muy mal"; "los inconvenientes"; "sacrificar una cosa o la otra": a primera vista esta retórica de violencia y renunciamiento, apenas mitigada por el deber patriótico y continental que le impone Waldo Frank, ${ }^{1}$ es poco apropiada para hablar de un nuevo espacio y de una nueva aventura cultural, y corresponde más a la obligación engorrosa que al descubrimiento feliz. Refleja, eso sí, una característica importante de la imagen de Nueva York en Ocampo, su recurso a una lógica de reemplazo. Nueva York, a través de su obra, sustituye otro espacio de producción cultural, mejor conocido por Ocampo, París, pero nunca pierde (será uno de los argumentos de este trabajo) su carácter inasible, indefinible. Como Trac, aquel cocinero vietnamita de Gertrude Stein que, al nombrar frutas y verduras, llamaba por ejemplo a la manzana "no una pera" y a la frutilla "una guinda no guinda", Ocampo construye Nueva York por aproximación y exclusión, acudiendo a lo familiar para obliterarlo, pero no suprimirlo del todo, de manera que quede, como en un negativo fotográfico, la imagen de lo contradicho en potencia, contaminando la perspectiva. Resumiendo esa lógica, puede decirse que Nueva York, para Ocampo — además de ser "no Santiniketan"— es París-no-París. Y también Buenos Aires-no-Buenos Aires. O, como ella misma escribe, en letras mayúsculas: es OTRA COSA. ${ }^{2}$

No es mi propósito analizar aquí en detalle el lugar y el modo de representación de Nueva York dentro del imaginario cultural argentino. Solo quiero señalar algunas características de esa representación que encuentren

1 En la autobiografía, Ocampo no solo recalca el "sacrificio" que constituye el viaje sino la ordalía del viaje en sí, tan incómodo por el mar revuelto, que tuvo que pasar la mayor parte del tiempo en cama, cuando "rara vez me ataca el mar" (Autobiografía VI 65). Todo, en este viaje, incomoda.

2 Imposible no asociar este "OTRA COSA" con el intento de autodefinición de Ocampo en su autobiografía, igualmente dificultoso: "Soy lo otro. ¿Pero qué?" (Autobiografía I 61). 
eco, o acaso origen, en el texto de Ocampo. Nueva York es la ciudad que queda fuera del itinerario, ritualizado y provechoso, que sancionan años de dependencia cultural. En notable contraste con otros latinoamericanos, provenientes sobre todo de México y del Caribe, el argentino (pese al viaje pedagógico de Sarmiento) no viajaba con frecuencia a Nueva York o, por lo menos, no viajaba a Nueva York directamente. Aún en los años cincuenta del siglo pasado (es decir, cien años después del viaje de Sarmiento) el viaje directo entre las dos ciudades era la excepción y no la regla. Se iba a Nueva York de vuelta de Europa, es decir, Nueva York no era meta sino escala del otro viaje cultural, el verdadero; era como una yapa. En el famoso boleto de avión "triangular", Buenos Aires/París/Nueva York/Buenos Aires que se precipitaban a comprar los viajeros, Nueva York era el vértice menos prestigioso del triángulo, no tanto desvío cultural como ventaja económica: a Nueva York se iba de compras, pero no se compraba cultura. La propia Ocampo reconoce esa tradicional falta de interés por Nueva York, de la que los salva, dice, a ella y a sus compatriotas, la oportuna intervención de Waldo Frank: "[a]lgunos (entre los que me cuento) le debemos a Frank el haber vuelto la mirada hacia el Norte de nuestro continente. Hasta entonces - salvo raras excepciones, y pienso en Sarmiento - la teníamos continuamente fija en Europa" ("Postadata a Waldo Frank", Testimonios $7^{a}$ serie 178$) .^{3}$

Nueva York, en el primer viaje de Ocampo en la primavera de 1930, es, por cierto, terra incognita, como anuncia el perfil de la ciudad, obliterado por la neblina a medida que el Aquitaine entra en dársena. La llegada, en más de un aspecto molesta, queda resumida, como a menudo en Ocampo, en el detalle frívolo pero significativo: "[h]acía calor y el calor siempre me ha incomodado. Me ahogaba con un tailleur de lana (el más lindo tailleur de la colección Chanel 1930, que debí dejar casi abandonado a causa de la temperatura" (Autobiografía VI 65). El traje francés, superlativamente elegante, no sirve en Nueva York, hay que abandonarlo. A Nueva York no se la puede prever y no hay guion que permita descifrarla:

Nueva York no era para mí más que una nueva, inmensa gran ciudad desconocida. No me siento atraída sino por las ciudades jalonadas de recuerdos o de sueños personales. Y todavía no había soñado con Nueva

3 Señala agudamente Cristina Iglesia el carácter iniciático de este viaje "americano" en su sentido más amplio: "[e]l primer viaje americano de Victoria Ocampo arranca en Europa, hace escala en Nueva York, atraviesa el canal de Panamá y toca puertos del Pacífico hasta llegar a Valparaíso"(117). 
York. Había conocido París, Londres, Roma, desde mi infancia. Y jamás he hecho otra cosa que retornar a ellas, donde viví — por lo demáscontinuamente (París y Londres) a través de los libros. Había conocido Madrid cuando tenía 18 años sin que dejara rastros en mí. Nueva York era absolutamente nueva. (Autobiografía VI 65)

Pese a Waldo Frank, por cierto empeñado en hacerle ver este viaje a Nueva York como retorno a "Our America", ${ }^{4}$ la ciudad resulta completamente nueva y completamente extraña; menos espacio de reflexión (Ocampo ha ido para continuar sus conversaciones con Frank) que espacio de incorporación: "la ciudad, lo inédito de su grandeza (a partir de la entrada en su puerto) me asombró a tal punto que olvidé casi el resto. [...] Mi apetito de Nueva York era omnívoro. Iba desde un rascacielos hasta un griddle cake" (Testimonios $7^{a}$ serie 179$)$.

Significativamente, para cifrar su desconcierto ante la ciudad, Ocampo recurre a una suerte de exotismo a la inversa. A la bruma inicial que le esconde el perfil urbano de Nueva York sigue la percepción, desde su ventana sobre Central Park, de un desorden primordial, donde el ruido del tráfico y las sirenas de los autobombas se mezclan con los rugidos de leones y tigres del zoológico de Central Park, particularmente de madrugada, cuando le impide dormir "el antediluviano y lejano rugir de la fiera enjaulada" (Testimonio $7^{a}$ serie 180 ). Años más tarde, en su segundo viaje, recurrirá una vez más a la nota exótica al describirle a Caillois las grandes mansiones neoyorquinas: "[e]n todas las grandes casas (suerte de palacios de estilo híbrido) y en todos los museos, hay siempre grandes patios cubiertos con fuentes y plantas que recuerdan el trópico. Imagínate que por momentos tengo la impresión de estar en Río aquí. Cosa que no me ocurre nunca en B.A." (Correspondance 198). ${ }^{5}$

La jungla urbana atravesada por refugios de fieras y los patios de Nueva York que remiten a Río de Janeiro (ciudad que apenas conoce): propongo que este insólito exotismo, que desplaza a Nueva York hacia el trópico, no es un mero acercamiento del tipo de las Lettres persanes de Montesquieu sino una manera de manejar la extrañeza fundamental de una nueva ciudad americana, más americana (en el sentido de no europea) que la propia Bue-

4 "Estoy viviendo en tu América, esperando tu regreso (parece ser un regreso de todo, esta primera visita tuya a Nueva York)" (Frank a Ocampo, 24 de enero de 1930, citado en Autobiografía VI 94).

5 Salvo indicación, las traducciones del inglés y el francés son mías. 
nos Aires donde nunca tiene la impresión de estar en Río pero sí de estar en París. “¿Estábamos en la selva o en la metrópoli más moderna del planeta? [Añade.] Todo era inverosímil" (Testimonios $7^{\circ}$ serie 180). Desde esa inverosimilitud describe Ocampo el grupo humano que más le interesa; no la muchedumbre neoyorquina que a menudo llama la atención del viajero (piénsese en "Coney Island" de Martí), sino la colectividad negra:

En ese primer breve viaje a Nueva York, fueron los negros los que me interesaron en primer lugar, porque les encontré más sabor que a los blancos. El americano del Norte me parecía un inglés deslavado, como después de haber estado en España, el americano del Sur me pareció un español desteñido. Ingleses y españoles, al atravesar el Atlántico y remojados en el crisol habían perdido el color. (Autobiografía VI 70)

Los negros neoyorquinos encarnan la diferencia norteamericana. Antes bien, la representan en el sentido teatral del término. Esto literalmente: Ocampo queda deslumbrada con la representación de Green Pastures de Marc Connelly en el Mansfield Theatre. ${ }^{6}$ Pero también asiste a otro tipo de performance, va en compañía de Waldo Frank y de Emmanuel Taylor Gordon al Cotton Club, donde la orquesta de Duke Ellington la lleva a declarar que "[l] a violencia rítmica del jazz de Duke Ellington es única. Me haría volver a Nueva York, aunque no fuese más que para sumergirme de nuevo" (125). Con los mismos acompañantes va también al Savoy, y, junto a ellos y Sergei Eisenstein, a un servicio en una iglesia evangélica negra. Harlem, obligación turística entonces como ahora, se ve como "un gran teatro" (71) y los negros como "actor[es] nato[s]": pasaría horas, dice Ocampo, escuchándolos cantar, viéndolos bailar, o simplemente caminar, "como gatos", por la calle (71). El espectáculo de la Nueva York negra le causa impresión, y Ocampo le dedica más de un texto. Envía una descripción de su visita a Harlem, en francés, y en prosa resueltamente "artista", a su familia (Cartas a Angélica 42-46). Retoma la misma descripción, ampliándola, en una conferencia que da en Madrid al año siguiente en la Residencia de Señoritas y que luego publica como ensayo en su primer tomo de Testimonios. Finalmente, dedica varias páginas a los negros de Nueva York en el tomo sexto de su autobiografía.

6 Inexplicablemente, al describir la obra, declara que "El papel de Jehová es encarnado por un blanco. Los demás actores son negros" (Testimonios $1^{\circ}$ serie 121). El actor que representaba a Dios era un conocido actor negro, especialista en Shakespeare, Richard Harrison, quien, a su muerte, en 1935, había representado el papel 1657 veces. 
En todos estos ejercicios se observa la misma entusiasmada negrofilia, para usar el acertado término de Petrine Archer-Straw, la misma objetivación del sujeto negro (tiene "sabor", tiene "color"), la misma simpatía paternalista (los negros le recuerdan a los criados y criadas de su infancia y los juegos que compartía con los hijos de ellos) y el mismo desaprensivo racismo. En todos, el negro funciona como fetiche, para significar, como alteridad vigorosa y a la vez estéticamente persuasiva, una diferencia norteamericana que solo más tarde formulará Ocampo en términos distintos. ${ }^{7}$ Cuando procura formularla, sin embargo, volverá a recurrir al estilo "guinda-no-guinda" del cocinero de Stein: “[C]ambié de opinión. El americano no me pareció más un inglés deslavado o un español desteñido, sino OTRA COSA, un nuevo producto en elaboración" (Autobiografía VI 70). El americano - ya sea el del norte o del sur- no es copia inferior del metropolitano sino un otro respecto del metropolitano. ${ }^{8}$

Ocampo usa el término testimonio, género en que escribe su obra entera, como título del capítulo que cierra su primera colección de escritos (también titulada, desde luego, Testimonios). El ensayo está dedicado a Alfred Stieglitz y a su galería neoyorquina, An American Place. Por su lugar al final del volumen y por su título redundante, "Testimonio" sirve por un lado de epílogo y por otro de manifiesto programático, extensivo a los lectores que comprenden su americanismo. Cito el último párrafo de ese texto:

Hombres y mujeres que sufrimos del desierto de América porque llevamos todavía en nosotros Europa, y que sufrimos del ahogo de Europa porque llevamos ya en nosotros América. Desterrados de Europa en América; desterrados de América en Europa. Grupito diseminado del Norte al Sur de un inmenso continente y afligido del mismo mal, de la misma nostalgia, ningún cambio de lugar podría definitivamente curarnos. De continuo amenazados por el temor a ver la tierra - en que querríamos echar raíces - dejar de ser tierra, esto es: alimento para convertirse en trampolín que nos invita al salto, a la partida hacia la otra ribera.

7 Prueba de esta equiparación entre lo negro y lo diferente americano sea acaso el hecho de que el primer (y durante bastante tiempo, único) poeta americano que publica Sur sea Langston Hughes, traducido por Borges en el segundo número de la revista.

8 Que Ocampo llegue a esta revelación ya implícita en Sarmiento y elaborada en Martí (a quien sin duda no ha leído) tan tardíamente parecería apoyar la propuesta de Carlos Alonso en su The Spanish American regional novel: Modernity and autochtony, acerca del carácter iterativo de los planos de modernidad en América Latina. 
An American Place... Jamás se me habría ocurrido un oasis que pudiera tener este nombre. (Testimonio 300)

Esta fervorosa proclama - que, como indica Blas Montero- simplifica una coyuntura cultural para realzar el rol heroico que se atribuye a Ocampo en el American Place de Stieglitz en Madison Avenue, ${ }^{9}$ por primera vez en su estadía neoyorquina reconoce físicamente un espacio, lo hace suyo, se siente por fin, dice, "como en mi casa" (Testimonio 296). Este reconocimiento instantáneo se completa con la lección de Stieglitz, quien comparte con ella, más allá de la "casa", el espacio urbano:

El día de mi visita a su estudio, cuando Stieglitz hubo acabado de mostrarme sus fotografías y los numerosos lienzos de Georgia O'Keeffe, Marsden, Narin, Dove, nos aproximamos juntos a una nueva ventana. Nueva York subía frente a nosotros, en grandes surtidores de rascacielos. Stieglitz me señaló con un ademán la ciudad: "I have seen it growing. Is that beauty? I don't know. I don't care. I don't use the Word beauty. It is life". (Testimonio 298)

\section{Como apunta agudamente Beatriz Sarlo,}

Nueva York le permite pensar Buenos Aires de un modo diferente de lo que, hasta ese momento, le había permitido París. En efecto, la relación Buenos Aires-París (o Londres) era una relación marcada por la ausencia de cualidades en uno de los dos puntos: Buenos Aires no tenía lo que tenía París. Ahora bien, en Nueva York, Victoria Ocampo descubre una ciudad que tampoco tiene lo que tiene París y que tampoco tiene lo que tiene Buenos Aires y que sin embargo es igualmente fascinante. Nueva York le enseña otra posibilidad, americana, de la cultura. (135)

En sus comienzos, Sur trabaja esa posibilidad, se presenta como reflexión sobre OTRA COSA americana, pero la postura americanista de la revista, como bien lo han observado John King y Cristina Iglesia, es inestable, difícil de mantener, pronto reemplazada por un previsible cosmopolitismo de raigambre europea.

9 Su tercera galería neoyorquina. Stieglitz tuvo dos estudios previos, uno de ellos en el célebre 291 Fifth Avenue. 


\section{USA 1943: An American Place y París-no-París}

En sus Memorias, Waldo Frank describe el malestar que siente en París, el hecho de que "el europeo occidental presentaba una suficiencia [completeness] que dejaba algo fuera, algo que no necesitaba para vivir y que América necesitaba. El hispanoamericano con quien me había cruzado tampoco tenía esa suficiencia, y esa carencia, como la mía, equivalía a su insuficiencia fecunda" (128). Aunque Ocampo cita este pasaje haciéndolo suyo en uno de sus ensayos sobre Frank, ${ }^{10}$ la noción de insuficiencia fecunda, ideológicamente hablando, no prospera en su obra como en la de Frank. Insuficiencia, sí; fecunda, no: Ocampo tiende a presentar su insuficiencia como circunstancia patética (para gran irritación, por ejemplo, de Virginia Woolf), no como provocación ni como ventaja cultural. Waldo Frank, también unido a Europa (recuérdese que escribe Our America a pedido de Gastón Gallimard y de Jacques Copeau), se despoja de su influencia al formar una unión (simplificada, idealizada) con la otra América cuya base es una compartida "deficiencia": a medida que el eje Norte-Sur se fortalece, Europa, y en especial Francia, pierden su brillo. En Ocampo, en cambio, la operación es mucho más vacilante, los resultados mezclados, cuando no contradictorios. A pesar suyo, y a pesar de los ambiciosos planes que Frank forja para ella y para su revista, Ocampo nunca permite que las Américas desplacen del todo la atracción, tanto emocional como ideológica, de Europa; esa suficiencia, precisamente, tan estéticamente satisfactoria. Esa ambivalencia, que ya puede observarse en el primer número de Sur pese a la declaración de principios, también lleva a Ocampo a acumular imágenes disímiles de Nueva York, en cuanto centro fuerte de cultura.

Recuerdo esta presencia de Europa, de Francia en especial, en el americanismo de Ocampo - si es que cabe darle tal nombre- para considerar esas nuevas, notablemente contradictorias imágenes de Nueva York que propone a distintos lectores en su segundo viaje a los Estados Unidos en 1943. En mayo de ese año, invitada por la Fundación Guggenheim, Ocampo pasa seis meses en ese país, la mayor parte del tiempo en Nueva York, dando conferencias. Como en el caso del viaje de 1930, hay una versión de esta estadía, en cartas, por un lado, y en testimonios por otro. Cabe aquí una reflexión sobre el género utilizado para medir plenamente el impacto de estas nuevas reflexiones sobre la ciudad. ¿Cómo se escribe una ciudad, y para quién se escribe? La cuestión que deliberadamente evité al comienzo, dejando que el

10 "Las Memorias de Waldo Frank", en Testimonios $9^{a}$ serie, 35. 
proyecto de Ocampo hablara por sí mismo sin preguntarme por sus lectores o interlocutores, merece ahora mayor consideración.

El lugar, esto es, la descripción de un lugar, es siempre producto de una dislocación, tanto geográfica como narrativa, de un traslado o traducción. Al practicar la escritura de viaje, escribimos acerca de los lugares donde hemos ido o adonde han ido otros cuyos textos hemos leído. Toda escritura de viaje cuenta con conocimientos previos, cuenta además con una complicidad entre narrador y lector, en la que el primero hace inteligible el espacio narrado mediante una serie de maniobras que remiten a códigos compartidos: yo estoy aquí y tú no, pero yo puedo hacerte ver lo que veo (o lo que me han dicho que estoy viendo) porque, en un sentido, tú ya lo conoces (es decir, ya lo has leído, aun cuando lo estés leyendo por primera vez). Si bien Ocampo no es precisamente escritora de viajes — sus testimonios son curiosamente estáticos-, sí asume una complicidad semejante con su lector.

En más de un aspecto, estos testimonios se asemejan a las crónicas modernistas: son relatos de una viajera cosmopolita a un público de compatriotas, menos ilustrados, que se han quedado atrás - tanto de modo literal como figurativo-, pero que pueden seguirla. En este sentido, los testimonios sobre Nueva York cumplen una función pedagógica. Esto ya era observable en los textos sobre el primer viaje de Ocampo: la expedición a Harlem, en su primera versión, fue una conferencia, impartida a las alumnas de la Residencia de Señoritas de Madrid, y el ensayo sobre Stieglitz, como se vio, era una propedéutica americanista. Otro tanto ocurre con "USA-1943", cuya intención didáctica (reflejada en el uso de fotografías y en esto semejante al primer número de $S u r$ ), si bien sutil, es indudable.

La función pedagógica que cumplen estos testimonios no es necesariamente una función informativa, documental. En Ocampo además hay poca descripción del espacio en sí. Declarándose inepta para tomar notas, escribe: "una fatalidad parece perseguirme. Jamás he apuntado en ellas nada utilizable o interesante. En cuanto no me dirijo a alguien (como en las cartas), en cuanto no tengo mentalmente un interlocutor para cortarle lo que veo, siento, observo, pienso, las palabras se me marchitan" (Testimonios $3^{a}$ serie 218). Al lector/interlocutor se le enseña a gozar con la ciudad, a sentirla, no necesariamente a conocerla en detalle. Con la excepción de Harlem, de los Cloisters (volveré sobre ellos) y de sus hoteles (el Sherry Netherlands en el primer viaje, el Waldorf Astoria en el segundo), no abundan las indicaciones espaciales en los textos. No sabemos, por ejemplo, por qué barrios camina. No sabemos si tiene idea de Buenos Aires. Acaso fuera pedirle demasiado: 
la mirada de clase se aúna aquí con la perspectiva de alto modernismo que trabaja el conjunto urbano más que la desagregación barrial. Ocampo comparte con el lector la emoción, no la localización.

Hay en "USA-1943" una soltura que no existía en los textos de viaje de 1930, un "como estar en casa" que denota no solo una familiaridad nueva con el espectáculo urbano, sino cierto entusiasmo que a falta de mejor nombre llamaré cultural. Esta vez no se viaja a la "nueva inmensa gran ciudad desconocida": esta vez sí se trata de un retorno. El prefacio de "USA-1943" retoma el diálogo con Stieglitz de 1930, recuerda la visita a An American Place, a Stieglitz mirando los rascacielos y preguntándose Is this beauty? Con la diferencia de que en, este viaje, Ocampo responde ella misma a la pregunta: “¿Quién lo duda, querido Stieglitz! La belleza ya nació junto a la vida en su desconcertante país. [...] He aprendido no solo a admirar sino a querer a los Estados Unidos: eso es lo que quiero decir sin tardanza" (Testimonios $3^{\circ}$ serie 215 ).

Mencioné el entusiasmo de este texto, su aparente ligereza, su tono excitado. No poco tiene que ver con este tono el hecho de que los Estados Unidos han entrado por fin en la Segunda Guerra Mundial y esta se manifiesta en una serie de detalles que rompen con la rutina ciudadana, creando una atmósfera febril cuya energía, entre gozosa y desesperada, capta admirablemente Ocampo:

Era la segunda primavera de la guerra en Manhattan. Los adolescentes fanáticos hacían cola para escuchar a su ídolo, Harry James, y los diarios empezaban a inquietarse con esta locura. La trompeta magnífica difundía a su alrededor quién sabe qué hipnosis. En los dancings, los muchachos y muchachas de uniforme, mejilla contra mejilla, bailaban sus adioses al son de As Time Goes By (Casablanca, Warner Bros. Picture). Las colegialas se enamoraban de Humphrey Bogart. Había que esperar semanas para ver Oklahoma (The Theatre Guild), musical play, éxito de la temporada, pero no para oírlo. Las canciones de esa opereta habían invadido la ciudad: "Oh! What a beautiful mornin'..." "People will say we're in love..." El duque de Windsor cenaba en el Ritz y tiraba miguitas de pan a los patos del lago microscópico que allí tienen. Fiorello La Guardia desafiaba a la Luftwaffe a que viniese a bombardear sus dominios. Nueva York era - decía - el "blanco número uno" de la guerra. Pero todo estaba preparado para recibir la visita de esos señores. Se hacían periódicamente ensayos de obscurecimiento. En la voz de Frank Sinatra se hamacaban millares de ensueños. Los marineros del "Richelieu" se paseaban por Broadway con la gorra de pompón rojo ladeada sobre la cabeza, 
sin comprender una palabra de inglés. Lentamente el "Normandie" se enderezaba sobre las aguas del Hudson. En Central Park, en Pennsylvania Station, los enamorados se besaban en la boca en pleno día. Tenían poco tiempo que perder y les importaban un bledo los espectadores. El azúcar estaba racionado: solo daban dos terrones para el desayuno. En las tiendas, ya casi no había elástico para ligas. Solo se tenía derecho a un reducido número de zapatos por año. Había cada semana un día sin carne.

A pesar de múltiples pequeños inconvenientes, aquella juventud parecía estar in the pink, a las mil maravillas. (Testimonios $3^{a}$ serie $245^{-246}$ )

En este tenor, resueltamente optimista, risueño y conservador - la escritura misma parece estar in the pink - continúa el resto del texto de "USA-1943". Ocampo observa el racionamiento de taxis; es interrogada y reprendida en una exposición de armamentos de guerra por tomar notas: visita el centro naval de entrenamiento de la WAVES en el Bronx, aprovecha para declarar su feminismo, y se entusiasma con los uniformes diseñados por Mainbocher; se queja de los chicles que ensucian las aceras de la ciudad; regresa a Harlem, donde, después de un servicio, la presentan al predicador Father Divine, no por su nombre sino como "South America"; descubre doughnuts, las hamburguesas, las griddle cakes, "cuyo sabor. . . se descubre poco a poco, a fuerza de comerlos" (260) y que se echan de menos, proustianamente, en cuanto se sale del país. Importantemente, Nueva York le permite a Ocampo un contacto con una pujante y exitosa cultura popular urbana - las cafeterías, los griddle cakes, los musicals, Frank Sinatra, el cinematógrafo, el jazz - que hasta ahora desconocía o desdeñaba, y que de pronto adquieren legitimidad cultural.

Me ha ocurrido muchas veces subir hasta el último piso del Empire State Building. De codos en el parapeto me gustaba mirar hasta sentir vértigo a Manhattan surgiendo del suelo. Pensaba entonces en la trompeta de Harry James, que se lanza sin vacilaciones gasta las notas más agudas y se mantiene allí, mientras los adolescentes fascinados se miran extáticos en ese espejo sonoro.

Es corriente decir que París no es Francia, ni Buenos Aires la Argentina, ni Nueva York los Estados Unidos. No lo creo. Quien toca a Manhattan toca a Whitman, como asegura Lewis Mumford, y quien toca a Whitman toca a los 
Estados Unidos en una de sus encarnaciones más asombrosas, bajo una de sus formas más excesivas, espléndidas y desordenadas.

Y si algún consejo tuviera yo que dar a esta metrópolis, se reduciría a

Submit to no model

but your own, oh City. (267)

Ocampo reclama para sus testimonios la inmediatez y la interlocución personal de la correspondencia: "[y] o no consigo articular mis sentimientos, mis observaciones, mis pensamientos sino por el placer y la prisa de comunicarlos directamente a X, Y o Z (un X, un Y, un Z bien determinados)" (Testimonios $3^{\circ}$ serie 218). Sin embargo, no todo queda registrado en ese género: en el prefacio a "USA-1943" escribe que "[a]lgo de lo que más me conmovió en USA ha quedado en cartas dirigidas a dos o tres amigos. Algún día, después de otro viaje (que será el tercero), quizá trate de aprovechar ese material" (214-215). Acaso las numerosas cartas a Roger Caillois escritas durante ese viaje (y solo publicadas recientemente) fueran parte de este "material" que quedó al margen de "USA-1943", desaprovechado en vida de Ocampo, ahora aprovechable para la crítica.

En 1943, Roger Caillois está en Buenos Aires, donde lo ha sorprendido la guerra. Huésped de Ocampo, ha fundado, con su ayuda, la revista francesa del exilio, Lettres françaises, de portada idéntica a Sur. Como los lectores de las crónicas modernistas, o como las señoritas del internado de Madrid, Caillois no conoce Nueva York, ni siquiera habla inglés. En cierto sentido también él se ha quedado atrás, de manera tanto más dramática cuanto que la mayoría de sus compatriotas exiliados se han refugiado en Nueva York. ${ }^{11}$ Ocampo, que ocupa la posición fuerte de esa relación, "conoce" Nueva York, tanto la ciudad como a sus gentes, habla inglés, y last but not least, es, para Roger Caillois, la "mujer mayor" bien conectada, examante y mecenas. Ocampo le "cuenta" Nueva York a Caillois, pero una Nueva York notablemente diferente de la que ofrece al público lector más amplio de "USA-1943". Distinto punto de vista, distinto género, distinto interlocutor, distinto propósito: otra ciudad. A estas diferencias cabe agregar una diferencia temporal. Si bien el viaje es el mismo, no así el momento de su escritura: las cartas de Caillois se escriben inmediatamente, mientras Ocampo está en Nueva York. La escritura de los testimonios está mediada por la distancia temporal y geográfica: Ocampo redacta el texto "USA-1943" ya de vuelta en la Argentina, al año

11 Sobre el tema de la emigración francesa a Nueva York, véanse Nettelbeck y Mehlman. 
del viaje, en Mar del Plata, durante el verano de 1944. Con su viaje de 1943, Ocampo no solo arma una imagen de Nueva York que difiere notablemente de la imagen que había propuesto en 1930, arma dos imágenes de Nueva York que difieren notablemente entre sí.

Si nos atenemos solo a la lectura de las cartas de Caillois, olvidando por un momento la lectura de "USA-1943", Nueva York no se presenta como an american place, o más bien, no solo como an american place. Los conocidos o amigos norteamericanos de Ocampo de la década anterior han sido desplazados por otra comunidad que de algún modo conoce mejor (y que Caillois sin duda conoce mejor), la de los intelectuales franceses exiliados en Nueva York durante la guerra. Ocampo retoma amistades interrumpidas: Jacques y Raissa Maritain, Denis de Rougemont, Saint-John Perse, y pasa buena parte de su tiempo tratando de armarle giras de conferencias a Caillois, para que se reúna con ella. Nueva York, en estas cartas, dista de ser la ciudad llena de vigor que ha pintado antes. Ocampo admira, sí, cierta fuerza técnica, atómica y estandarizada, cuya metáfora sería perfectamente una sincronizada actuación de las Rockettes de Radio City. Aquello es "bello como los autos y los puentes, bello como los aviones que vuelan en V, como los pájaros" (Correspondance 189). ${ }^{12}$ Pero la imagen de Nueva York que comunica a Caillois es, sobre todo, la de una ciudad melancólica, lugar de nostalgia y de morosos inventarios, donde se rememora no la lejana Buenos Aires, no la Nueva York de diez años antes, sino el París borrado por la guerra. Cuando Ocampo va al museo, el retrato de Montesquieu pintado por Whistler le recuerda la vez en que Montesquieu por equivocación se le metió en el cuarto a su hermana Pancha en el Majestic, y ese recuerdo, le escribe a Caillois, "hizo que me atragantara con París" (Correspondance 198). Cuando va a una exposición, las puntas secas de Helleu son como "un álbum de fotos de familia" (200). Cuando emprende una conversación en el hotel, es con una norteamericana "que ha vivido treinta y cinco años en París y ha escrito un libro, La Francia que amo" (200). Cuando sale

12 Esta belleza estandarizada (norteamericana, podría decirse), se complementa, para Ocampo, con la otra, la artística (la europea, la que ella y Caillois comparten). Así, después de elogiar a las Rockettes, observa: "[p]ero no olvidemos que hay también algunos grandes escritores que han llegado a la cumbre, a otras cumbres, por otros caminos. La belleza de ellos no es la de la estandarización. Poco importa que por el momento esa belleza sea menos popular (¡y cuánto!) que la otra. Poco importa incluso que esté relegada. Existe y algún día triunfará. No seamos demasiado impacientes" (190). El uso del nosotros es aquí notable. 
de paseo, va a los Cloisters a ver la tapicería del unicornio, o más bien su reproducción fotográfica, ya que los originales se han mandado al depósito durante la guerra. O bien va a la dársena a ver el Normandie varado en el Hudson, el mismo barco que, de no haberse declarado la guerra, hubiera llevado a Paul Valéry a Buenos Aires, "y parecía que esa especie de enorme osamenta quemada, vomitando agua por todos los orificios, y enderezándose tan lentamente que el movimiento era casi imperceptible a la vista, era el símbolo de muchas cosas" (202). La "horrible melancolía" que dice sentir solo es mitigada por el espectáculo del Richelieu, anclado más arriba en el Hudson, con sus banderitas francesas que le recuerdan, dice, la bandera de la Cámara de Diputados en la Place de la Concorde, tan bella de noche. Esta reconstrucción de París inaccesible y derrotado de 1943, París del cual el Normandie es símbolo, reemplaza a Nueva York en estas cartas. Si bien subsisten en ellas pequeños restos de una cotidianeidad diurna, la ciudad se borra para dar lugar a la ausencia de la otra, se vuelve lugar de duelo. Funciona en esta correspondencia como negativo de París, hasta en las recriminaciones: "[c]omprendo que para los europeos la estadía en las Américas sea una especie de purgatorio (infierno para algunos). Pero no es culpa de las Américas que hacen lo que pueden. Y es gracias a las Américas que los europeos respiran en estos momentos" (188). Prueba adicional de esta francofilia que opaca entusiasmos americanos es el hecho de que nunca aparezcan en esta correspondencia nombres de amigos norteamericanos de Ocampo, como Alfred Stieglitz, Lewis Mumford, los Young Intellectuals que le ha presentado Waldo Frank. Solo aparece el nombre de Langston Hughes, "le poète nègre" (189), como lo describe Caillois. De nuevo Nueva York negra, pero solo en un encuentro episódico. Refiriéndose años más tarde a esta estadía en Nueva York filtrada por una amenazada sensibilidad francesa, escribe Ocampo: "Francia estaba allí pero como en un ataúd. Ya era Grecia" (Testimonios $7^{a}$ serie 131 ). ${ }^{13}$

13 Esta extraña noción de que Nueva York se ha vuelto el museo de París se vuelve explícita en "Cocteau en Nueva York" (Testimonios $7^{a}$ serie 130-138). La contrapartida de esta construcción de Nueva York es la que le devuelve el propio Caillois cuando por fin llega a Nueva York, solo, en 1945. Mucho más disponible, a pesar de su falta de inglés, Caillois describe una ciudad llena de contrastes, asombrosa pero no melancólica (Correspondace 216-221). Caillois extraña, sí, la mirada de Ocampo: "[m]ucho quisiera que estuvieses aquí. Quisiera que me mostraras las cosas, las vería mejor contigo. Temo verlas de pasada, o al revés. Porque, entre otros méritos, tú sabes hacer ver" (217). 


\section{Viajes posteriores: deriva}

Las dos imágenes de la ciudad - la animada Nueva York de la guerra, el swing y los griddle cakes, o la Nueva York llena de exilados franceses desde donde se añora París-, si bien condicionadas por los interlocutores a quienes están destinadas, resumen además de la ambivalencia de Ocampo, una suerte de inseguridad cultural. "Siempre he sido mala viajera porque mis verdaderos viajes prescinden de aviones, de transatlánticos, de ferrocarriles. Y sin embargo, de no haber viajado, habría mucha gente -o mejor dicho algunas personas y algunas cosas- que no habría conocido nunca" (195), escribe Ocampo a Caillois. Mientras no aparezcan esas "quelques personnes et quelques chaises" que suministren asidero para la futura memoria, anclando el recuerdo de lo que se ve por primera vez y volviéndolo prestigioso, es decir, digno de ser atesorado, hay un desajuste. Así entre Nueva York y Ocampo: una frase de una carta a Caillois es elocuente: "[n]ada de lo que siento, nada de lo que amo tiene appeal para este país. Esto me deprime a ratos, pero sé que es tonto esperar otra cosa. Ni el momento, ni las circunstancias me son propicios. Lo importante es permanecer flexible" (Correspondance 19o). La resignada frase, con sus ecos flaubertianos, parece más desengaño amoroso que decepción cultural. Habla más de malentendidos que de desencuentros ${ }^{14}$ o que de una relación significativa con la ciudad y sus gentes. Esta desazón, tan elocuentemente captada en la frase a Caillois, suplanta la curiosidad del primer viaje y el ambivalente entusiasmo del segundo. En viajes posteriores a 1943 la desazón es más pronunciada, se traduce en errancia, deriva sin rumbo: "[a]yer volví a casa, pues, y como tenía hambre me fui a comer un griddle cake a la cafetería del Mayflower de la Quinta Avenida. Caminé un poco; miré las tiendas. Entré en las tiendas. Salí por el calor. Me volví a meter en otras por el frío de la calle. En cuanto me calentaba salía. En cuanto me enfriaba entraba de nuevo por alguna revolving door de gran tienda" (Cartas a Angélica 104). Nueva York toda parece una revolving door, adonde se entra sin cesar y de donde sin cesar se sale, pero donde uno nunca se aposenta. Significativamente, entre la gente que ve Ocampo en Nueva York en estos viajes posteriores se destacan los exiliados, a su vez expertos en revolving doors. No se trata ya de exiliados franceses sino, a excepción de Stravinsky y su mujer, de exiliados en su mayoría hispanohablantes: Gabriela Mistral, Francisco Ayala, Victoria Kent.

14 No descarto desde luego el hecho de que estas cartas estén dirigidas a un examante cuya pérdida bien puede haber influido en la representación de la ciudad. Nueva York significa un duelo doble: por Francia y por una relación. Sobre el tema del malentendido en Ocampo, véanse Sarlo y Molloy. 
Aunque a partir de 1943 Ocampo viaja a menudo a Nueva York, su contacto con la cultura de la ciudad, y de Estados Unidos en general, no se volverá por ello más profundo. Señala John King cómo esta falta de contacto se ve reflejada en las mismas páginas de Sur, de donde casi desaparecen las colaboraciones norteamericanas: "Estados Unidos seguirá siendo un aliado durante la guerra fría, pero no se registraría su desarrollo cultural" (King 140). Nueva York es lugar de encuentros fugaces con interlocutores cuyo prestigio es más social que intelectual y que, como ella, ejercen cierto mecenazgo: la familia Crane, Nelson Rockefeller, Mildred Bliss, por ejemplo. Nueva York es también el lugar de cierto desamparo: "[a]noche pues, me fui a vagar por las calles, a buscar un cine que me sirviera de compañía" (Cartas a Angélica 146$).{ }^{15}$

Esto no significa que Nueva York no deje su marca en la perspectiva de Ocampo, problematizando (si bien no reemplazando) su relación con Europa y sobre todo con Francia. Si París fue filtro para ver Nueva York en las cartas de Ocampo a Caillois, Nueva York, en esta última etapa de los viajes de Ocampo a los Estados Unidos, se vuelve filtro para ver París. Esta perspectiva contaminada queda notablemente captada en una carta de 1963:

Hace tiempo que no llegaba de N.Y. a París (generalmente salgo de aquí para allá). La impresión es distinta. [...] Las calles preciosas siempre, son (dado lo que traigo en los ojos) las de una maravillosa ciudad de provincia deslumbrante [...] París es Roma (aunque no sé cómo estará Roma): incomparable pero $[\ldots]$ pièce de musée, en cuanto a la época contemporánea cuyo "exponente" sería Nueva York. (Cartas a Angélica 151)

"Todo resulta más chico" (151), concluye Ocampo, comparando a París con Nueva York. Y en carta a otra hermana, hablando de Detective Story, el film que acaba de ver en París, observa: "[c]uando vi las calles de New York $\mathrm{y}$ aparecieron los americanos, $\mathrm{y}$ hablaron, y se movieron en la pantalla fue como si respirara aire fresco y volviera a casa. [...] Veo las calles de Nueva York y respiro" (174). Así como en la Nueva York de 1943 se añoraba París, en París de la década de 1960 se añora Nueva York.

15 Cuando en 1979 se me pidió un artículo sobre Victoria Ocampo en los Estados Unidos, me fue sumamente difícil rastrear a sus amistades neoyorquinas. Hablé al azar con Vera Stravinsky, con Victoria Kent y Louise Crane, con Sylvia Marlowe. Nadie parecía tener una idea clara de lo que hacía en Nueva York, salvo que iba mucho al cine: "parecía deprimida", recuerdo que me dijo Marlowe. 
Nueva York, al final, no habrá sido para Ocampo verdadera ciudad de trueque, como las de Calvino, "caracterizadas por intercambios: de recuerdos, de deseos, de recorridos, de destinos" (14) - y cabría añadir, de culturas - Estuvo muy cerca de serlo: de haber prosperado el proyecto con Waldo Frank, Sur acaso habría sido otro American place y Nueva York se habría vuelto una de las capitales de Ocampo, el tercer vértice, vital, del triángulo. Son conjeturas. En cambio, la Nueva York de Ocampo queda como lugar de contactos más que de relaciones y de cierta soledad. Si bien altera la estructura binaria de la cultura europeo-argentina de Ocampo, modificando su percepción de Francia, no se impone lo suficiente para que la haga culturalmente suya: para que se vuelva, verdaderamente, lugar de intercambio.

\section{Obras citadas}

Alonso, Carlos. The Spanish American Regional Novel: Modernity and Autochtony. Cambridge: Cambridge UP, 1990. Impreso.

Archer-Straw, Petrine. Negrohilia: Avant Garde Paris and Black Culture in the 1920's. New York: Thames and Hudson, 2000. Impreso.

Benjamin, Walter. Sentido único. Trad. Alfredo Brotons Muñoz. Madrid: Akal, 2015. Impreso.

Caillois, Roger y Victoria Ocampo. Correspondance. Ed. Odile Felgine y Laura Ayerza de Castilho. París: Stock, 1997. Impreso.

Calvino, Italo. Le città invisibili. Turín: Einaudi, 1972. Impreso.

Frank, Waldo. Memoirs of Waldo Frank. Ed. Alan Trachtenberg. Boston: U of Mass. Press, 1973. Impreso.

Iglesia, Cristina. "Waldo y Victoria en el paraíso americano: identidades y proyectos culturales en los primeros años de la revista Sur". Boletín del Centro de Estudios de la Teoría y Crítica Literaria 8 (2000): 113-124. Impreso.

King, John. Sur: A Study of the Argentine Literary fournal and Its Role in the Development of Culture, 1931-1970. Cambridge: Cambridge UP, 1986. Impreso.

Mehlman, Jeffrey. Emigré New York: French Intellectuals in Wartime Manhattan, 1940-1944. Baltimore: Johns Hopkins UP, 2000. Impreso.

Molloy, Sylvia. Acto de presencia: la escritura autobiográfica en Hispanoamérica.

México DF: FCE - El Colegio de México, 1997. Impreso.

Nettelbeck, Colin W. Forever French: Exile in the United States 1939-1945. Oxford: Berg, 1991. Impreso.

Ocampo, Victoria. Autobiografía I. El archipiélago. Buenos

Aires: Ediciones Revista Sur, 1979. Impreso. 
Ocampo, Victoria. Autobiografía VI. Sur y Cía. Buenos

Aires: Ediciones Revista Sur, 1984. Impreso.

Ocampo, Victoria. Cartas a Angélica y otros. Buenos

Aires: Sudamericana, 1997. Impreso.

Ocampo, Victoria. Testimonios. Madrid: Revista de Occidente, 1935. Impreso.

Ocampo, Victoria. Testimonios $3^{a}$ serie. Buenos Aires: Sudamericana, 1946. Impreso.

Ocampo, Victoria. Testimonios $7^{a}$ serie. Buenos Aires: Sur, 1967. Impreso.

Ocampo, Victoria. Testimonios $9^{a}$ serie. Buenos Aires: Sur, 1975. Impreso.

Ocampo, Victoria. Testimonios $10^{a}$ serie. Buenos Aires: Sur, 1975. Impreso.

Sarlo, Beatriz. La máquina cultural: maestras, traductores y

vanguardistas. Buenos Aires: Ariel, 1998. Impreso. 